\title{
Evaluation of Scientific Thinking of Zakaria Razi about the World of Natural and Cosmology
}

\author{
Mohammad Esmail Esmaili Ahangar ${ }^{1}$ \\ ${ }^{1}$ Graduated Phelosophy Sience Ph.D, BabolCity, Iran \\ Correspondence: Mohammad Esmail Esmaili Ahangar, Graduated Phelosophy Sience Ph.D, BabolCity, Iran. \\ E-mail: esfehani.mohamad3@gmail.com
}

Received: January 3, 2016

Accepted: January 26, 2016 Online Published: June 21, 2016

doi:10.5539/ass.v12n7p88

URL: http://dx.doi.org/10.5539/ass.v12n7p88

\begin{abstract}
In the fourth and fifth century of $\mathrm{AH}$ (tenth and eleventh. m) all science, especially natural science and cosmology were interest to people particular to scientists. These centuries was in a row of the best periods of prosperity, science and culture and became famous in the history and civilization of "the golden age of Islamic Iran". As a result, new scientific findings add to the scientific achievements of the past and also influenced the minds of scientists in the later centuries. Razi had a big contribution in the development of philosophy and natural sciences at the beginning of the fourth century AH equal to the tenth century AD and achieve the highest degrees in their time in various fields. Razi raised the opinion of the ancient alchemy of Khamse, and also transformed elixir to chemistry. And was founded the core of chemistry and give chemistry to the medicine. among what was written in the third to seventh century of $\mathrm{AD}$ about race (the ninth to the thirteenth century), we find many cases that all of them express his accurate method in the clinical experimental method. Razi not only experiences in medicine but also knew tests as essential topics in the natural sciences. Human scientific past was known by thoughts of scientists such as Razi and their theories are the cornerstone of philosophers thinking of recent history. Therefore, this article seeks to examine the scientific thinking of Razi about the world of nature and cosmology. For this purpose, the method of library and tools of notes taking was used.
\end{abstract}

Keywords: nature philosophy, evolution, Zakaria Razi

\section{Introduction}

Philosophy and the natural sciences philosophy is kind of cosmology that is discussed the Intellectual system of human about the world and examined the time (time) and where (space) and interaction and their influence on other aspects of human civilization. Is the social, political, cultural, religious situation of each historical period influenced the philosophical attitude? While in ancient Greek philosophy was as a basis of thought current and philosophers like Aristotle believed that with the help of the reasoning and rational thought can reach to the mysteries of the universe. In other words, mind based on the reasoning has the ability to decode the universe. In the middle ages in the European countries, the philosophy of natural science was situated on the side of the metaphysician but was used as a means to justify religious beliefs. In the Renaissance with the development of natural science, a new perspective of knowledge opened for the mankind. in The ancient Greek, philosophers and scientists offer their theories with the run on pure reasoning methods and limited view of things scientific, that its result was the formation of philosophical schools like Tally an, Pythagoreans, Platonists, Aristotelians and nuclear. In fact, the development did not stop. And in each period, the thinkers emerged in the field of philosophy of natural science that knew the possibility of understanding the secrets of the universe impossible and expressed the discussion of "Agnosticism 'or lack of understanding of the universe. But in the East Asian civilization like Iran philosophy has always been associated with spirituality and religion. Rather in accurate words, the natural sciences in Iran have evolved in the form of religious history. In fact, the philosophy of natural science completely internalized and mixed up with religion. Iran's pre-Islamic religions like Zoroastrianism, Sabian, Mithraism and Manichaeism had a philosophical dimension.

People like Kai choro, James hakim, bozorg mehr and names like these is such as signs of love and wisdom with Iran's religious principles in the history of philosophy.

Their differences are with Plato and Aristotle that he has not been to develop a philosophical book and perhaps wrote his views on philosophy and the natural sciences but due to historical accidents they lost their scientific 
work and these do not reach to us. Plato's admitted in the book of Republic based on that he had learned philosophy from Iranian shows analysis truth.

Georgie Zidane writes: "Alexander Macedonian after the conquest of a capital of Iran burned some part of their books and translated partially and sent them to Alexandria and Aristotle. At that time, Iranian had gathered treasure of India, China, and others in the capital. "(Georgie, 1993, p. 546). So Aristotle had the pieces of Persian and Babylonian science. What is significant is that maybe the scientific and philosophical achievements of antiquity was transferred to the Islamic era and maybe that's why the vast territory of the Transoxiana in the East to the Andalusia in the West thinkers emerged that not only has authority in various fields of science, such as philosophy, theology, mathematics, astronomy, chemistry but also in terms of prosperity and development their efforts were changed in the fields of philosophy and science knowledge. In this regard can noted thinkers such as Razi. Review of the scientific literature by scientists such as Razi, Ibn Sina, and aboreyhan Biruni tell their service to humanity and their influence on the world scientific community, especially Europe contemporary era. They count as the most influential and the most important scientists of that period that created the intellectual foundation of Iran and the Islamic world in subsequent periods because their vision and scientific theory have generality and universality in terms of time and subject. Therefore, understand and explain them about the basics of intellectual and scientific nature is necessary. However, the imaginary of these scientists in the field of the scientific theory is not limited to an age and a specific territory. Razi By combining the movement of medicine Hippocrates and Galen and the chemistry introduced a new concept. The purpose of this article is an introduction to scientific thinking about the natural world and Zakaria Razi. because them, as one of the greatest philosophers and writers of the fourth and fifth century of $\mathrm{AD}$ equal to the tenth and eleventh lunar, has a huge role in the development of science in Iran and the world. While recognizing his intellectual foundations cause his knowledge of general theories of Hermetic schools, Platonic, new Pythagoreans and mathematicians, historians, philosophers, and naturalists Peripatetic philosophical views of Zoroaster, Mani and the thinking of ancient Persia.

\section{Fourth and Fifth Centuries AD: Peak of Irans Scientific Activity}

Fourth and fifth centuries in accordance with the tenth and eleventh century AD are the height of Iran's scientific activities (If you do not consider the University of Jondi Shapur of Sassanid era). In this period, the Greek books, Syria, Pahlavi and Hindi were translated by translators that these translations are in the access of scientists. Experts and scientists wrote explanations and interpretations about these translations. Now it's time that scientists became busy by using the scientific resources and paying to research and scientific debate and try themselves to produce the science and the renaissance in science. These people dare say that it was both experts and theorists like Abu Nasr al-Razi, Group Akhvalsfa, Avicenna and Biruni and others were trained in various disciplines.

These people have the courage to disagree with the views and concepts common to the era.

Even trace them concepts and superstitious religious and traditional fiction books and articles written during that period. We could say that experts and theorists like Abu Nasr farabi, Zakaria Razi, the Group of Akhvalsafa, Avicenna and Biruni and others were trained in various disciplines. These people have the courage to disagree with the views and common concepts of that era. Even they wrote a trace on the concepts and religious and superstitious and traditional fiction books and articles during that period.

Contrary to the impression of some people, scientists and intellectual people are not the only persons that would impact on the thought and science environment, but also the environmental conditions also affect breeding and genius scholars. If we want to examine the account of the life and scientific work of a thinker and philosopher and scientist, first the requisite of all the society of his time is necessary. In fact, knowledge of the current political, social, economic, intellectual and cultural era is needed. These factors lead to understanding the emergence of scholars better and evaluated the issues and their scientific activity objectively. Zakaria Razi biography and his scientific perspective

"Abu Bakr Muhammad ibn Zakariya Razi" is known as a philosopher and natural scientist and chemist in the West as Razi (Rhazes). He is a world-renowned Iranian figure in 864.AD. He was born in Ray of Iran and he died in the year 925 or 932.AD. In Baghdad he has spent most of his life in Baghdad. Zakaria Razi was a professor of medicine and logic in philosophy, mathematics, astronomy, chemistry (alchemy). He benefited Hindi, Persian, Greek and Arabic resources in his written and in addition to that he has added some issues to that (Defeat, 2003, p. 89).

Razi was living in an era where there was freedom of thought and opinion to some extent. If you see books in that era you can understand that at that time the mosque and temple KISA KES were situated together 
undisturbed. Authors were free in composing any kind of books. Books which are about the violation and start bidding, etc. remaining indicate that scientists were free in the expression of opinion and defend it.

That is why razi has been attacked after his death than during his lifetime. debates which have done with Abu Hatim Razi was in the house of one of the elders of (heads) Ray and the city judge and all the elders were present, but no desecration was said to the philosopher, physician, whom he regarded as heretics then (Ravandi, 1994, p. 143 ).

Razi has had an experimental inductive methods and attention to the affairs of the sensory research. Because he was a physician and Naturalist so he paid attention to the secret issues (Safa, 1995, p. 187), so the philosophical and religious ideas have a direct relationship with his scientific thoughts. And this scientific method became the main resin that he created in alchemy and medicine. Razi, on the one hand, served to the science that only checked material objects and on the other hand, picked up a long step between eliminating another kind of science that aims to understand spiritual things. We can say that Razi had a big role in the history of science. In his scientific approach, there is a close relationship between the scientific and philosophical and religious thoughts. We can perceive that the perspective of a scientist about nature never is far from his overall vision of reality. The main reason of razi getting away from the way of ambition and self-interest and the pursuit of scientific direction and service to science is as his philosophical views. Razi is a thinker who merely discursive reason originality. His clinical studies in medicine represent his research method is based on observation and experience.

In addition, to that, his philosophical views on Iranian culture and civilization, including the history of human thought is a liberal and freemen. Razi Unlike another Iranian philosopher that loves non-Iranian worldviews had the independence to the culture and worldview of ancient Persia. He is given richness to the philosophy of continuity and MOG and from the general sense of a worldview is being committed with an attitude of "material". Ibn Nadim writes: Razi was polite and generous benefactor to the people. He was treated with kindness to the poor and the needy people So that he accepted their representation and warranty in many cases them and nurse them in sickness and he was a financial contribution. He was reading and writing and transcription constantly. At the end of his life he was blind (Nadim, 2002: 531).

Zakaria Razi believes that philosophical science is not acquired, and no one worth of the name of the a philosopher, unless the alchemy industry won, too has no need of all people, and others require knowledge of him (ibid., p. 631).

\section{Razi's Views in Philosophy and Cosmology}

Razi in philosophy and cosmology believed five traditional creatures it means that from the time the world existed these five creatures also exist. These old five creatures are the creator, the breath, the primary monster (the first material), absolute space, and absolute time. In this regard, Nasser Khosrow was written "Heuvel companions as Iranshahr (Abul abas Iranshahri philosopher of the third century and the middle of the fourth AH) and Mohammad Zakaria Razi and one of them said that Heuvel is the old ink, Muhammad ibn Zakariya Razi have proved the old five creature; one is Heuvel, second time, third place, fourth breathe and fifth self-praise "(Naser Khosro, 2005: 68). And is the Creator of pure reason and pure science and living is shining from his life as the sun. And from the overall breath of life was scattered light (Henry, 1959: 209). However, as Razi was committed to the Iranian tradition, he knew light as the first creature, matter and space and time as old (Lahore, 2002: 41).

Razi new world was as a creature. About creating the world is said from sane hakim razi that it may happen by one of the two sides. Or by "nature" or by "will" if it is by "nature" is required to press the universe which is the narrator, and from here it is necessary that the narrator is makers. Because among the nature that is the source of creating will be created by a finite distance, but if it was by the "will" and require of makers comes from non-will creator to will creator will be another step with him, that he would act in this way and that old is "soul". And from here it is understood that Razi knew the world as the narrator. Unlike Aristotle that is considered the universe old in comparison with the creator step (tin, 1994: 71). Razi proved the Old mystery of matter (Heuvel) in this way. In the world nothing created unless of something else, it means that innovation is impossible and it is not possible that creator creates something from nothing. So it is necessary that Heuvel was being old arise materials (Safa, 1995: 172). "The survival or conservation of energy 'which was introduced around 1845 by several scientists came to the conclusion that the principle of conservation of energy was prevail all natural processes. This principle said, "Energy may be converted to another form, but can never be created or destroyed" (Benson, 2005: 197). Because Heuvel has no solution of location, location is too old. And with The first motivation of material time was formed. Of course, the motivation does not create time, but picking up the 
curtain from it (Hosseini koohsari, 2003: 40). He was discriminated between "time" and "period". As philosophers knew the time as a period which has beginning and end but "universe" is the time which has not any beginning and ending. He knew the term (universe) old and he knew relative time associated with the movements of the heavens and the stars. Absolute time or the total time of continuous ink and old is progressive and unstable that was exist before the creation of the universe and will exist after the corruption of the universe. He split places such as general location or absolute location and relative location or split partial addition place. The absolute unlimited location is independent and self-sufficient from the world and the things which are located in it (Sharif: 1983: 621, 626 and 627).

Briefly it is said, that the existence of these five things is the emergency. Because what is noticeable was heuvel which has combined because it may need location because it is the subject of various conditions it needs time. Because some of these states are a priority over others knew by the time step. Some of the creatures are alive, so the breath is necessary for them. And among them there are the wise and industries exist in extremely strong, so wise creators and peacemaker is necessary (ibid. 621).

Razi rejected compromise between religion and philosophy. (Unlike Peripatetics like Farabi) Even though he had faith in God because he was the physician and induction from experience and observation, of course, he doesn't a good relationship with the followers of Aristotle Peripatetic. Therefore, unlike theologians and some philosophers, he never can accept that we can compatible religion and religious with that philosophy. Because the religion's way is news and the way of philosophy is mind and thinking (tin, 1994: 75).

Moreover, Razi has critic all religions. To express his opposition to all religions, the book of "Al-Nabawi" that was famous to "incomplete interfaith" and was written "Hbl Almatin" known as "Makhareq al Anbiya'. With no doubt, Razi religions defect book contains the fiercest attacks to religions. That was formed in all ancient and medieval periods (Safa, 1994: 175-176; Ravandi, 1994: 135-136).

\section{Razi and Rationalism}

Razi is from material philosophers and thinkers of Iran. And is among those who accept nothing to imitation and obedience, but also to accept anything they get help from reason and argument. Razi put the first chapter of "spiritual medicine" to praise the virtue and wisdom, and said: A creator whose name being great gave us the wisdom to help us that in this world and the other world use all benefits which its reaches and the conclusion was deposit in the human essence. Wisdom was the greatest blessing of god for us. And there is nothing superior in benefit and interest more than that. By The wisdom, we lead the animals. With wisdom we reach to the thing which superior us and sweet our lives and we will reach to our wills and desire. this is wisdom by which we imagine our mental activity before it appears in the senses, as we understand it, it seems that we feel it, then appears these forms in our sensory verbs emerge their match with what we had more imagination. So because the mind has such a foundation degree and significance and magnitude and glory, it is incumbent on us to not reduce its dignity and its range. he is Amir, not captive him, while he is prince of that mind, don't bondage collar around his neck and not change subordinate to the commander. But we should refer to him in any Affairs and criteria in all wisdom and always rely on it. we shouldn't let Whimsy overcome it. we Should whim and forced austerity that we have to make it obedient. If we do so, we place value on our intellect and our apparent and benefit us (Ravandi, 1994: 137-138; Noble, 1983: 618-619).

Toughest teller asserting the primacy of reason (rationalists) even can't raise intellect so much and with such clarity. In Razi's point of view, our only criterion to gain science and for our practice is every mirror argument. And in this way should not be resorted to any non-rational force. Razi was totally opposed to the mystery of prophecy and revelation and against any non-rational thought (sharif, 1983: 619). Razi was too "(rationalists)" and rely on the wisdom Immeasurable. Although he has faith towards God, but his toughness towards rationalism left no location for inspiration and intuition (velayat, 2004: 253).

Ibn Ravandi and other thinkers of the material and Irans rationalists knew wisdom as the only Imam and leader of men. If we compare the reasons of "Ibn Ravandi" with the reasons of Zakaria razi in the rejection of prophecy, we can say that both is Reasoning with the same method. And it is the appeal from the wisdom and support of human thought. Ibn Ravandi said: "Reason is the greatest blessing for the people by which can recognize God and his blessings and for wisdom of the work orders encourage is necessary. If the prophet confirmed Praise and denounces and orders reason, so its invitation is aborted of our movement. Because it Needless our intellect and if ordered otherwise praise and denounced and ordered intellect command, then we shouldn't accept His Messenger (Ravandi, 1994: 142). Briefly we can say that Zakaria razi believed that wisdom alone is enough to identify good and evil, benefit and harm human life and recognition of God and the divine secrets (mysteries of God) and measure life and resurrection. 
This issue that Razi is the greatest opposes of the philosophy based on the revelation and Islam has led to this fact that with existing a mass of students, a high school of philosophy in Iran not notice. Usually, most Iran's philosophers were influenced by religion, so because of that it was attacked by scientists and philosophers of the next era. Including, Farabi who written the book of "In response to the Al-Razi in the divine science" (pooya, 1994: 131). Even BIRUNI who tried to collect his work and wrote a list of his works disagreed with philosophical thoughts of Razi. So, like alchemy and medicine was unable to leave his school philosophy (Nasr, 2006: 25).

\section{Razi's Evolutionary Perspective about Science and Philosophy}

Razi believes that the scientific and philosophical information is in progress and traveled the evolution in leaps. Ideas of Plato and Aristotle and other similar philosophers do not solve the problems of science in order to study and experience, unquestionable obedience of these votes, forcing the man to mark. If anyone knows that vote impenetrable and eternal he is following useless way. Razi says, of course, scientists will come after me that they reject some of the results which I have reached to them as he tried to put his teachings instead of predecessor's theories.

Razi is entered ideas and objections in the book of "Doubt on Galen" on medicine and philosophy involves. He also acknowledged the great respect and honor and dignity of Galen and his scientific proof for the truth of such a defense, "A lot of people have suffering me. Because I am cope up a man like Galen who is superior in all parts of philosophy. Art medicine and philosophy to submit to the leaders and accepting their speech doesn't accept Laxatives and philosopher doesn't expect his students this yield. As Galen in the book "benefits of members' interests" has reprimanded those who impose their followers without reason and what dared me to handle data and sends it easy on me, is that if he was alive did not blame me for writing this book and did not worry him, but also they were happy. I didn't count a person as a philosopher who blames me for extracting this involves, because he has betrayed the tradition of philosophers. This is Aristotle who said that the right and Plato disagree with each other and both of them are friends with us but right is more humanitarian from Plato to us. Because of these problems, if later on Afazeli and early referendum is to say, science is increasing over time and be close to perfection. What scientists have discovered a long time ago in a future scientist finds in a short time? Future scientists heir last. If it asked why the early scientist are top to the modern scientists we can say this claim is not true absolutely unless that modern was late to complete what has been paid earlier." (Razi, 2006, pp. 24-27).

\section{Conclusion}

Human scientific past was known by the thought of scientists such as Razi and their theories are the cornerstone of philosophers thinking of recent history. In fact, if they weren't, philosophers of the nineteenth and twentieth ages were unable to create works of philosophy. As some of the authors of the current era had interpreted the philosophical works of the philosophers in the past and at the same time added new findings on the philosophy history of science. Reconstructing the history and philosophy of science in Iran would be impossible without the work of predecessors.

Reconstruct the past and monitoring the development of science is essential. In fact, new theories should be based on the evaluation of the past but as a comparison can evaluate past Iranian scientists with the new theories in the contemporary world.

To clear the role and influence of Iran in the history and philosophy of science each generation used the legacy of past generations of his scientific discoveries, must have nearly as that much to preserve this precious heritage and enhance it. So that future generations can benefit from it. The history of human knowledge is throughout exchange among peoples and nations.

What was ethnic invented, other people accepted it and added the new content to it. Today most people have complained about some facilities and equipment. But few people speak about a little perseverance. Is Razi's and others' work instrument is comparable with modern facilities? So in a rational and logical analysis, it can be said: These were men of action and through observation, experience, accuracy, and with a strong ideology tried to discover the hidden secrets of the universe and in the shadow of labor and thought to reduce the number of unknowns. In this case it can be said that Razi was done study and research on various diseases and their wish was to discover the cause and treat the pain of human society pain. Generally, the Discursive and material thinkers in Iran and world aimed at improving human suffering and tried to rescue their people from storms unscientific ideas. Without relying on science and nature, man is not capable of having good ideas about the creation of life and other natural phenomena.

If asked why Iranians was the center of the human sciences, it must be said that science and philosophy 
inherently do no home and residence. Wherever the spirit of civilization provides comfort, security, and justice was following scientific activities, and initiatives to bring industry. Like the shadow of a man who is looking for someone. In fact, freedom of thought ruling values of the society of knowledge and science will provide the security context for scholars. If it came upon a history a time in the history of Iran, Greece, India, Egypt, Alexandria, was a cradle of science and technology and foster the knowledge and art, that is because at that time this country were provided for intellectuals, safety, welfare, and support. Yes, as long as the components which mentioned situation were in these lands, science and Technology and civilization center had established in these lands. But after insecurity of scientific activities went into decline, gradually Heritage of humanity moved to other territories.

Iran's land was one of the science areas that with the presence of various ethnicities and religions educated thinkers that developed part of science with their initiatives and innovations. such as algebra which was invented by Muhammad ibn Musa al-Kharazmi and today progress in a way that math is considered as one of the great fans. Or other sciences, such as medicine, chemistry, mathematics and physics that have come from other nations to the Iranians, Iranians added fresh and new content to it and made it richer. For example, Zakaria Razi made alchemy to chemistry and was converted it from a public monopoly to benefit everyone. Briefly, it is part of the human sciences scientists and philosophers thought of Iran. Maybe it was not so wrong that know the Iranian past history as physician, physicist, and mathematicians that were active alongside comments about astronomy, geometry, logic and ontology to theology and worldview. Razi has no coherent system of philosophy. But in comparison to the era in which he lived, he would be account as the powerful and so-called free-sighted thinkers in Islam, and perhaps in all of human history. He is a pure rationalist (asserting the primacy of reason) and had confidence to the power of infinite wisdom and was away from any prejudice and was dared in speaking out. He believed all the Almighty God to humanity and development and other religious faith but did not believe any religion (Noble, 1983, p. 633).

Razi believed that the philosopher's task is to awaken the people. If can present a book as an ultimatum and guides, is Scientific books, such as the Almagest Ptolemy, Aristotelian logic, Euclidean geometry and Hippocratic medicine. So Razi intellectual basis was positive about sciences. He believes that science should rule the world and science can be happiness of humanity. True prophets are not philosophers and scholars. In his opinion medical books, geometry, astronomy and logical were discovered by reason and without the help of prophets. With all that said, can be said that Razi has independent thoughts by His time did not adhere to the conventional method. And with an open mind look at the world tasks and preferred a way of rational, empirical and intuitive and logical deductive method.

\section{References}

Benson, H. (2005). Basic physics (1) (7th ed.). The translation of Bahari, MR, Payam Noor publishment.

Defa, A. A., \& Shoghi, J. (2003). Fame physics in Islamic civilization (1st ed.). Translation, Mohammad Reza, Publishing Institute for Humanities and Cultural Studies.

Georgie, Z. (1993). The history of Islamic civilization. translation, javaher kalam, Ali, the seventh edition, published by Technology, Tehran.

Halabi, A. A. (1994). History of philosophy in Iran and the Islamic world (1st ed.). Publishing mythology.

Hosseini Koohsar, I. (2003). Islamic philosophy (1st ed.). Published by Technology.

Ibn al-Nadim, Mohammad Ibn Ishaq. (2002). Alfehrest (1st ed.). Translation, Modernity, M., publishing mythology.

Muhammad Iqbal Lahore, M. (2001). The course of Iranian philosophy (1st ed.). Translation, A.j. Aryanpour, the first edition, look Publishing.

Nasr, S. H. (2006). Religion (in the modern world) (4th ed.). Scientific and Cultural Publications.

Pooya, A. (1994). Iranian philosophical thoughts, myths Publications (p. 131).

Qobadian, N. K. (2005). zad al mosaferin, correction, Emadi Haeri, Mohammad (1st ed.). Publishing written heritage.

Ravandi, M. (1994). A Social History of Iran (Vol. 10, 1st ed.). Publishing and publishing stroke Age leprosy America Arash Stockholm, Sweden.

Razi, A. B. M. ibn Z., \& Galen, A. A. (2006). Homeopathic philosopher. Translator, scholar, M., cultural figures Publications. 
Safa, Z. (1985). On rational sciences in Islamic civilization (the mid-fifth century) (Vol. 1, 5th ed.). Tehran University Press.

Sharif, M. M. (1983). The history of philosophy in Islam (Vol. 1). translation, under poor javadi, N., Tehran, University Publishing.

Thomas, H. (1969). Philosophical elder. Translation, Badrehee, Fereydoon, cultural, scientific publications.

Velayati, A. A. (2004). The dynamics of the culture and civilization of Iran and Islam (Vol. 1, 3rd ed.). Published by the Ministry of Foreign Affairs.

\section{Copyrights}

Copyright for this article is retained by the author(s), with first publication rights granted to the journal.

This is an open-access article distributed under the terms and conditions of the Creative Commons Attribution license (http://creativecommons.org/licenses/by/3.0/). 